\title{
Fractures of the Ankle Joint
}

Investigation and Treatment Options

Hans Goost*, Matthias D. Wimmer*, Alexej Barg, Kouroush Kabir,

Victor Valderrabano, and Christof Burger

\section{SUMMARY}

Background: Ankle fractures are common, with an incidence of up to 174 cases per 100000 adults per year. Their correct classification and treatment are of decisive importance for clinical outcome.

Method: Selective review of the literature.

Results: Ankle fractures are initially evaluated by physical examination and then by $\mathrm{x}$-ray. They can be classified according to either the AO Foundation (Association for the Study of Internal Fixation) or the Weber classification. Dislocated fractures need emergency treatment with immediate reduction; this is crucial for the prevention of hypoperfusion and nerve damage. Weber $A$ fractures can usually be treated conservatively, while Weber B and C fractures are usually treated with surgery. An evaluation of the stability of the syndesmosis is important for anatomical reconstruction of the joint. Wound hematoma and wound-edge necrosis are the most common complications, and the postoperative infection rate is $2 \%$. Up to $10 \%$ of patients develop ankle arthrosis over the intermediate or long term.

Conclusion: With properly chosen treatment, a good clinical outcome can be achieved. The long-term objective is to prevent post-traumatic ankle arthrosis. The evidence level for optimal treatment strategies is low.

\section{Cite this as:}

Goost H, Wimmer MD, Barg A, Kabir K, Valderrabano V, Burger C: Fractures of the ankle joint-investigation and treatment options. Dtsch Arztebl Int 2014; 111 : 377-88. DOI: 10.3238/arztebl.2014.0377

\begin{abstract}
ractures of the ankle joint are among the commonest fractures in adults, with an incidence of up to 174 cases per 100000 persons per year (1). For a good long-term functional outcome to be achieved, reliable early evaluation is crucial so that it can be determined whether the problem is a distorsion (sprain), ligament rupture, bony ligament avulsion, or fracture of the talocrural joint. The proper treatment is chosen on the basis of the mechanism of the accident and the correct classification of the injury and accompanying soft-tissue damage. The goal of treatment is to enable the patient to put his or her full weight on the joint once again without pain and to prevent permanent damage.
\end{abstract}

\section{Learning objectives}

This review should enable readers to recognize and classify the different types of ankle fracture reliably and to pursue the proper further diagnostic evaluation for each type. It also includes an overview and assessment of the various treatment options on the basis of selected articles from the literature.

This article is mainly concerned with fractures and therefore does not contain a detailed discussion of ligamentous injuries.

\section{Relevant anatomy}

The talocrural joint is the junction of three bony structures: the distal ends of the tibia and fibula and the trochlea of the talus. The tibia and fibula are elastically bound in the fork of the ankle joint by the ligamentous structures of the syndesmosis (interosseous membrane; anterior, posterior, and transverse tibiofibular ligaments) $(1,2)$. Powerful collateral ligaments stabilize the joint against stress from the

\section{Incidence}

Ankle fractures are among the more common fractures in adults, with an incidence of up to 174 cases per 100000 adults per year. 
sides: laterally, the anterior fibulotalar ligament (AFTL), fibulocalcanear ligament (FCL), and posterior fibulotalar ligament (PFTL), and, medially, the broad fan of the deltoid ligament and the plantar calcaneonavicular ligament (spring ligament), whose medial border is blended with the forepart of the deltoid ligament. Because the talus is asymmetrically shaped, movement in the ankle joint is not a pure hinge movement, but rather a rotatory hinging movement around the helical axis of the joint (3). Precise congruence of the ankle joint is essential for its proper function, and thus malpositions of traumatic origin have major adverse effects, as they alter the biomechanics of the joint and cause pathological compressive stress $(4,5)$.

Ankle fractures are generally to be regarded as joint fractures even if there is no fracture cleft in any of the articular surfaces of the joint. For the ankle joint in particular, non-anatomical reductions and restraints lead to premature degeneration of the joint. Thus, proper anatomical reconstruction-generally involving surgery-is needed to prevent posttraumatic degeneration over the long term.

\section{Epidemiology and etiology}

According to data for the year 2008 from the AOK (a large health-insurance carrier in Germany), ankle fractures cause nearly one million days off from work for every 100000 insurees per year (6). In 2011, there were nearly 75000 hospitalizations for ankle fractures in Germany (7). An evaluation of ICD-10 data for inpatient treatment in Sweden over a period of 17 years revealed an incidence of 71 cases per 100000 person-years. Nearly $60 \%$ of the affected patients were women, and the mean age of all patients was 52 years. Slightly more than half of all such fractures were due to falls, and $20 \%$ to traffic accidents $(8,9)$.

\section{Physical examination}

In our experience, it is hard to distinguish an ankle fracture from a ligamentous injury reliably on the basis of the initial physical examination alone. Clues to a probable ankle fracture include swelling, hematoma formation, and tenderness to pressure over the medial and/or lateral malleolus or over the proximal head of the fibula (high fibular fracture, the so-called Maisonneuve injury). Moreover, further associated bony injuries should be ruled out by palpation of the talus, the calcaneus, the navicular bone, the mid- tarsal (Chopart) joint, and the base of the fifth metatarsal bone for possible crepitation or local tenderness. As in all dislocated fractures, grossly visible malposition of the joint is an indication for immediate reduction with manual axial traction under adequate analgesia, followed by restraint of the joint in a splint. Characterization of the associated softtissue damage and the exclusion of compartment syndrome are important considerations for the planning of further treatment (10).

\section{Radiological evaluation}

If a fracture or a sprain with ligamentous instability is suspected, radiological evaluation is needed in practically all cases. The Ottawa Ankle Rules represent an attempt to hold the performance of imaging studies down to a clinically necessary minimum, in view of limited resources; they do not correspond to the diagnostic standard in Europe, however (11). The radiation dose (which is low) and the costs of $\mathrm{x}$-rays are much less important than the risk of missing a bony ligament avulsion or an osteochondral lesion. We therefore recommend the following procedure, which is at variance with the Ottawa Ankle Rules in some respects: Standard x-ray imaging of the ankle joint should be performed in two directions, anteroposterior ( $a-p$, the so-called mortise view) and lateral. If a fracture is suspected, the foot and the joint should be imaged without weight-bearing-in contrast to the weight-bearing views that are generally obtained with the patient standing in elective cases. Depending on the associated injuries that may be suspected, an additional dorsoplantar view or a lateral image of the foot may be indicated. Moreover, a Saltzman view can provide important information about the inframalleolar alignment (12). As in all fractures involving a joint line, computed tomography (CT) can be very helpful for precise evaluation (13).

Magnetic resonance imaging (MRI) is not indicated for the acute assessment of suspected fractures (14), but is often useful later on as an additional tool for the assessment of potential cartilaginous or ligamentous injuries. A standardized procedure should be followed for the reading and reporting of ankle images (Figure 1). This is crucially important, because the first physician to deal with the patient is often a relatively young and inexperienced resident on call, and standardization helps ensure that no bony injuries will be overlooked.

\section{Physical examination}

Clues to a probable ankle fracture include swelling, hematoma formation, and tenderness to pressure over the medial and/or lateral malleolus or over the proximal head of the fibula.

\section{Radiological evaluation}

As in all fractures involving a joint line, computed tomography (CT) can be very helpful for precise evaluation. 

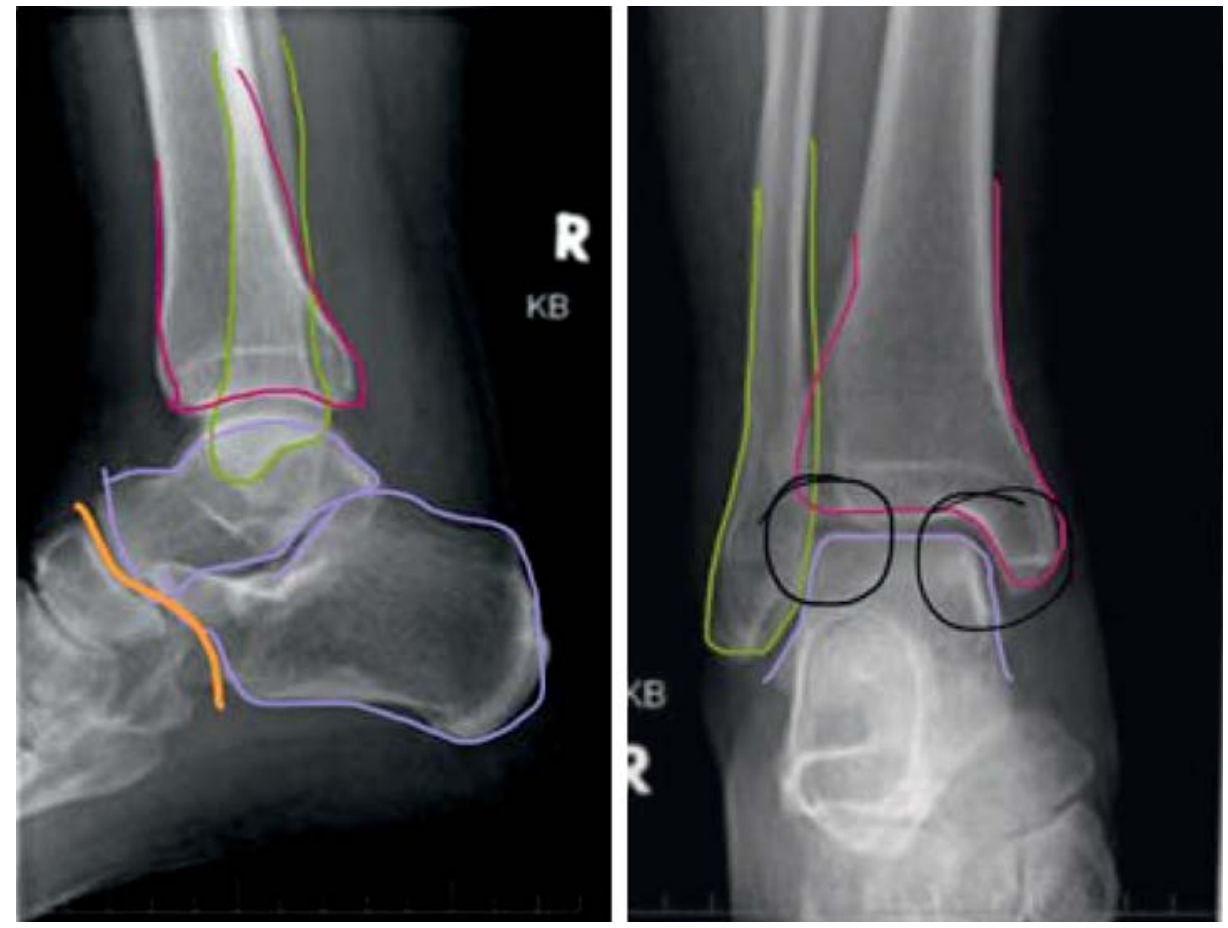

Figure 1: Algorithm for assessment of anteroposterior and lateral $\mathrm{x}$-rays of the ankle.

1. inspection around the fibula (yellow)

2. inspection around the tibia (pink)

3. inspection around the talus (purple)

4. check tibiotalar distance

5. check fibulotalar distance

6. final check of tibiotalar and fibulotalar joint congruence

7. inspection around the fibula

8. inspection around the tibia

9. inspection around the talus and calcaneus

10. check tibiotalar joint congruence 11. check cyma line (Chopart joint line)

\section{The classification of soft-tissue injuries and fractures}

In the German-speaking countries, soft-tissue injuries in the ankle region accompanying closed fractures are usually classified as described by Tscherne and Oestern, while those accompanying open fractures (which are rare in this joint) are classified as described by Gustilo (eTable) (15-17).

In routine clinical practice, the fracture itself is generally classified purely descriptively as a uni-, bi-, or trimalleolar fracture. This rough classification, however, gives too little information about the mechanics of the fracture. In contrast, the oftcited classification of Lauge-Hansen makes sense in terms of the underlying pathological mechanisms and is suitable for use in an academic setting, but we find it too complicated for routine use (18).

We therefore prefer the expanded Danis-Weber classification issued by the Association for the Study of Internal Fixation (AO Foundation) (eFigure)(19, 20).

\section{Classification}

In the German-speaking countries, soft-tissue injuries around closed ankle fractures are usually classified as described by Tscherne and Oestern, while those around open ankle fractures (which are rare) are classified as described by Gustilo.
According to this scheme, a lateral malleolar fracture below the syndesmosis is designated a type A injury; a fracture at the level of the syndesmosis, a type B injury; and a fracture above the syndesmosis, a type $\mathrm{C}$ injury. The Maisonneuve fracture is a special case, as it involves a high fracture of the fibula, typically below the fibular head, that is usually caused by an indirect pronation mechanism. In this type of fracture, the ankle joint is destabilized by a tear of the entire interosseous membrane of the lower leg, the syndesmosis, and the deltoid ligament.

Thus, a Maisonneuve fracture can also be considered a type of ankle-joint fracture-all the more so because it is often accompanied by bony avulsion of the posterior syndesmosis on the dorsal side of the distal portion of the tibia (the so-called Volkmann fragment).

An anterior avulsion of the syndesmosis on the ventral side of the tibia is called a Tillaux-Chaput fragment (only in adolescents), while an avulsion on the fibular side of the ventral syndesmosis is called a Wagstaffe fragment $(21,22)$. 




\section{Emergency treatment}

Emergency treatment begins with immediate clinical examination of the entire, unclothed lower limb, which enables assessment of the state of the soft tissues, the perfusion status, and possible nerve injuries. In cases of obvious malposition, immediate reduction is indicated; this is to be done by traction along the long axis under appropriate analgesia to minimize pain. It is unacceptable for a patient to be delivered to the hospital by the emergency medical services with an obviously dislocated joint (Figure 2) without any attempt at reduction, regardless of the specialty qualifications of the physician in the emergency response team. In our experience, patients generally cannot be harmed to any significant extent either by a successfully executed reduction or by an unsuccessful attempt; on the other hand, if the joint is left in its dislocated state, the softtissue injury may worsen irreversibly. This can lead, in turn, to a delay of surgery in the best case, or, in the worst case, to internal pressure necrosis with further sequelae up to and including amputation (Figure 3). Moreover, the leg must be assessed for soft-tissue pressure, peripheral perfusion, and motor and sensory function to rule out a potential compartment syndrome.

Whenever a fracture is suspected, e.g., when the joint is painful and its mobility is limited, stabilization of the joint with a splint is obligatory unless and until a fracture is ruled out. Cooling of the joint should be undertaken with caution, if at all, to avoid cold injury to the soft tissues (23). The formal evidence level for the optimal emergency treatment of ankle fractures is low by the currently accepted criteria of evidence-based medicine.

\section{Treatment indications and options}

When an ankle fracture has been diagnosed, the choice of a suitable treatment depends not only on the fracture type and associated injuries, but also on the patient's other medical conditions, and any treatment can only be provided with the patient's informed consent (Table). In the rest of this article, we present the main decision criteria and a clinical approach to treatment that we have found useful in practice. It is important to note that, at present,

\section{Emergency treatment}

Whenever a fracture is suspected, e.g., when the joint is painful and its mobility is limited, stabilization of the joint with a splint is obligatory unless and until a fracture is ruled out.

\section{Treatment indications and options}

When an ankle fracture has been diagnosed, the choice of treatment depends not only on the fracture type and associated injuries, but also on accompanying medical conditions. All treatments require the patient's informed consent. 
decisions to operate or not to operate are supported only by low-level evidence. The results of several randomized trials that are currently in progress should become available in the near future (24).

\section{Conservative treatment}

In principle, any stable fracture with non-displaced or only slightly displaced fragments can be treated conservatively. The procedure to be followed depends mainly on patient compliance. Type A fractures need not be immobilized in a cast, but can rather be treated like external ligament ruptures in a stabilizing ankle orthosis for early function with pain-adapted full weight-bearing.

All fractures that are not of type A should be treated in a so-called walker or vacuum shoe. Leg casts made of plaster or a synthetic material are relatively uncomfortable for the patient and therefore, in our opinion, obsolete. Over a period of six weeks, the patient should be mobilized in a walker for pain-adapted full weightbearing (25). The orthosis stays on at night. If the patient cannot bring full weight to bear on the ankle because of the fracture type or because of pain, the administration of an antithrombotic drug during this period should be considered (26).

The potential complications of conservative treatment include the displacement of fragments and widening of the ankle fork during the further course. We therefore recommend obtaining follow-up x-rays $4,7,11$, and 30 days after the causative trauma.

Depending on the overall findings, it may be entirely reasonable to treat a fracture conservatively and to accept healing in an imperfect position in an elderly or multimorbid patient, if the risk of surgery is judged to be high (27). In such cases as well, the joint is generally immobilized with a walker or a vacuum shoe.

\section{Surgical treatment}

Surgery is indicated for the following types of fracture (AO Foundation classification):

- grossly dislocated AO-44A-1 fractures

- displaced and unstable AO-44A-2 and 44A-3 fractures

- dislocated AO-44B-1 fractures

- all other fractures from AO-44B-1.2 and up.

Every ankle fracture is, by definition, a joint fracture. The goals of surgery are, therefore, always the smooth anatomical reconstruction of the joint
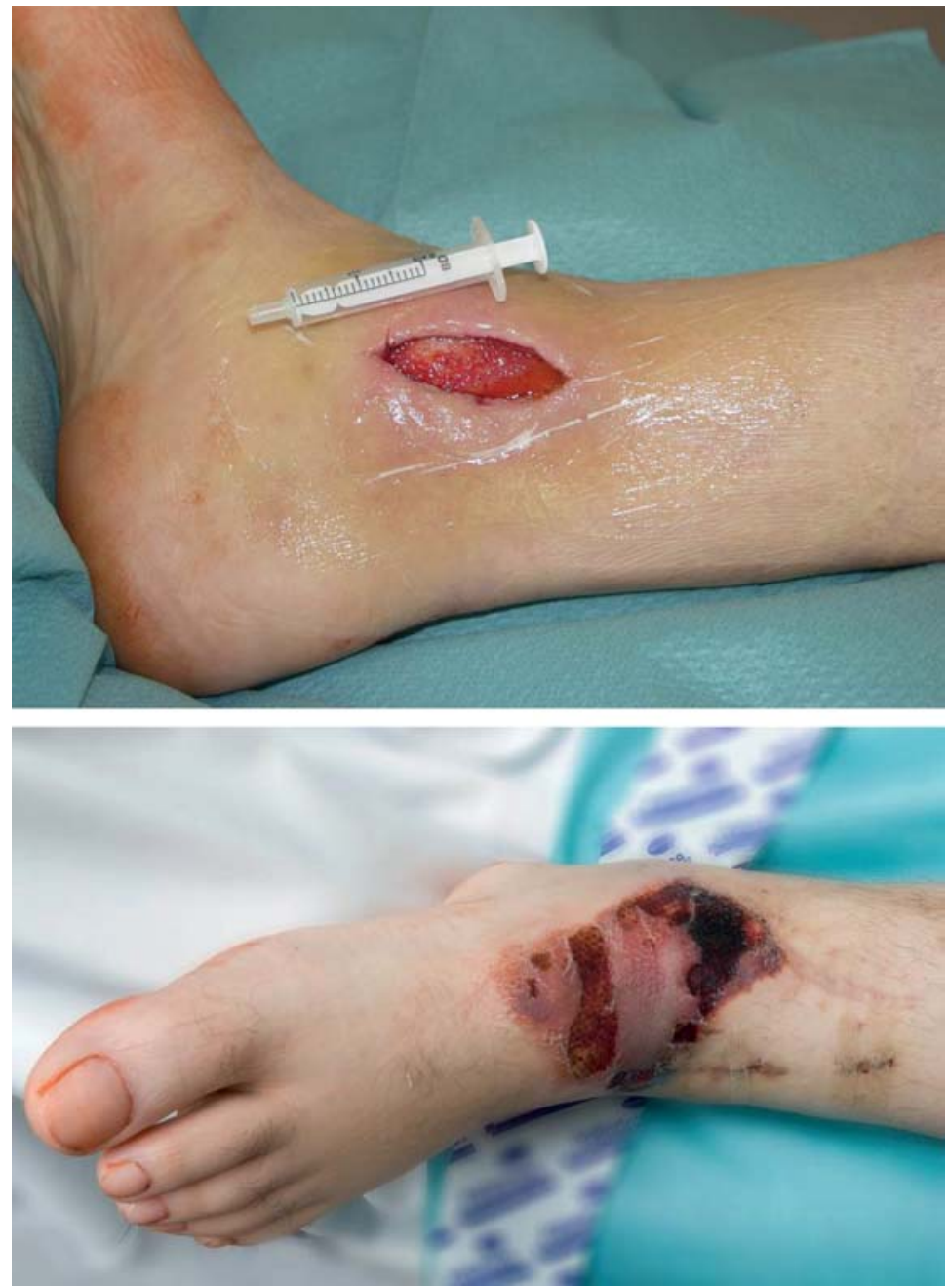

Figure 3: Ulcerative tissue defects due to pressure from within in longstanding, untreated, non-repositioned ankle fractures

surface and the protection of the injured ligamentous structures to enable early postoperative functional therapy of the joint. Malalignment of the joint is more common, however, than direct injury to the tibial, talar, or fibular joint surface. The reconstruction of the joint surface in such cases therefore, initially, involves the correct setting of the length, axis, and rotation of the fibula and of the tibiotalar and fibulotalar distances, as well as the reduction of Volkmann's triangle, if necessary. If the obligatory $\mathrm{x}$-ray check

\section{Elderly patients}

Depending on the overall findings, it may be entirely reasonable to treat a fracture conservatively and to accept healing in an imperfect position in an elderly or multimorbid patient, if the risk of surgery is judged to be high.

\section{Surgical treatment}

The goals of surgery are always the smooth anatomical reconstruction of the joint surface and the protection of the injured ligamentous structures to enable early postoperative functional therapy of the joint. 


\section{Complications of ankle fractures}

\begin{tabular}{|c|c|c|c|}
\hline Treatment & Timing & Diagnosis & Possible management \\
\hline \multirow[t]{6}{*}{ Conservative } & \multirow[t]{4}{*}{ short-term } & compartment syndrome & fasciotomy \\
\hline & & dislocation & osteosynthesis \\
\hline & & inner pressure ulceration & osteosynthesis, arthrodesis, plastic surgical coverage \\
\hline & & CRPS & pain therapy, plexus block \\
\hline & \multirow[t]{2}{*}{ long-term } & pain & arthrodesis, ankle prosthesis \\
\hline & & limited range of motion & arthrodesis, ankle prosthesis \\
\hline \multirow[t]{12}{*}{ Surgical } & \multirow[t]{7}{*}{ short-term } & compartment syndrome & fasciotomy \\
\hline & & wound hematoma & wound revision \\
\hline & & impaired wound healing, infection & wound revision \\
\hline & & dislocation & reoperation \\
\hline & & malpositioned screw(s) & reoperation \\
\hline & & inadequate reduction & reoperation \\
\hline & & CRPS & pain therapy, plexus block \\
\hline & \multirow[t]{5}{*}{ long-term } & non-union & resection and bone grafting \\
\hline & & malposition & correction osteotomy, arthrodesis, ankle prosthesis \\
\hline & & impingement syndrome & arthroscopy \\
\hline & & limited range of motion & arthrodesis, ankle prosthesis \\
\hline & & arthrosis & arthrodesis, ankle prosthesis \\
\hline
\end{tabular}

CRPS, complex regional pain syndrome

after reduction and casting of the fracture reveals that the proper position of the joint cannot be maintained, then reduction should be performed again under general anesthesia and the fracture should be temporarily or definitively set.

The timing of definitive surgical treatment depends mainly on the soft-tissue findings. Immediate, definitive surgery is possible only if the soft tissues are not critically vulnerable. This is generally the case only within a temporal window of a few hours after the traumatic event.

In all other cases, surgery should be deferred until swelling around the joint has subsided and wrinkles have reappeared in the skin. If surgery is performed while the soft tissues are still swollen, it may be technically impossible to close the wound without excessive tension. This, in turn, elevates the risk of wound-edge necrosis and wound infection.

\section{The timing of surgery}

The timing of definitive surgical treatment depends mainly on the soft-tissue findings. Immediate, definitive surgery is possible only if the soft tissues are not critically vulnerable; this is usually true only for a few hours after the trauma.

\section{Surgical technique}

Surgery is usually performed with the patient supine, in either general or regional anesthesia. The prophylactic administration of antibiotics before surgery is standard procedure (28). A tourniquet is used, or not, depending on the surgeon's personal preference, as tourniquets have not been shown to shorten the operative time or to make the outcome any better or worse (29). The management of the soft tissues is very important for the patient's postoperative recovery (30). The plates and screws usually used in Germany are part of what is called the "small-fragment instrumentarium" and are made nearly entirely of titanium, except for the wires.

Ankle arthroscopy before the osteosynthetic procedure, or as a preliminary part of it, may help the surgeon discover hidden osteochondral lesions and check the anatomical reduction (31). 
The removal of osteosynthetic material is medically indicated only if it protrudes painfully beneath the intact skin, or if beginning ulceration is present after complete bony fusion (32). In the absence of an obligatory medical indication, the required informed consent for such operations is analogous to that which must be obtained before elective cosmetic procedures.

AO/Danis-Weber type A fractures

An isolated type A fracture of the lateral malleolus should only be treated with open reduction and internal fixation (ORIF) if there are dislocated fragments and/or joint involvement.

Displaced fractures of the medial malleolus are usually located at the angle of the joint in the area of transition to the tibial joint surface. Without treatment, the talus swings into a varus malposition over the patient's further course. Depending on the findings, the joint surface can be reconstructed by open or closed reduction. The reduction is held together by two small cannulated or conventional smallfragment traction screws. Alternatively, tensionband wiring can be used.

\section{A0/Danis-Weber type B fractures}

A Weber type B fracture may be an isolated fibular fracture or a fracture of the lateral malleolus combined with a fracture of the medial malleolus (a socalled bimalleolar fracture) or a Volkmann's triangle. The fibula is anatomically reduced (with special attention to proper length) through a standard longitudinal incision with longitudinal traction and, if necessary, rotation. The reduction is secured with a pointed reduction forceps or a fracture reduction forceps. The traction screw through the fracture is placed as nearly perpendicular to the fracture plane as possible to enable interfragmentary compression. The reduction is further secured and stabilized with a one-third tubular plate (neutralization plate), which is modeled to the bone and then fixed above and below the fracture with screws. In biomechanical terms, this plate serves as a strut or prop; a thin plate that can easily be bent with manual pressure suffices. If the fibula is broken in multiple fragments, no traction screw is used. Modern, anatomical, partly anglestable implants are now commercially available that make reduction technically simpler. The syndesmosis should also be tested for injury (see also below under "Injuries of the syndesmosis").
The medial malleolus and Volkmann's triangle are fixed in place in analogous manner to the procedure described below for type $\mathrm{C}$ fractures.

\section{A0/Danis-Weber type C fractures}

The operative technique is essentially the same as that for type B fractures. An ankle-stable plate can be used instead of a one-third tubular plate depending on the involvement of the joint. This is particularly useful if there is a long fracture zone with multiple fragments. The so-called Maisonneuve fracture, a high Weber type $C$ fracture under the fibular head, is a special case: in many such injuries, the syndesmosis and the interosseous membrane are torn and the fork of the ankle is, therefore, unstable. The fibula has to be positioned into the fibular notch. The Maisonneuve fracture itself, however, is usually not treated with an osteosynthesis.

\section{Injuries of the syndesmosis}

In any type $\mathrm{B}$ or $\mathrm{C}$ fracture, the ankle should be positioned intraoperatively in $20^{\circ}$ of internal rotation and pulled laterally with a retractor hook to test the stability of the syndesmosis. Lateralization of the talus, i.e., widening of the tibiofibular cleft or of the talotibial joint space medially, implies a biomechanically relevant rupture of the syndesmosis leading to instability. In such cases, the fibula has to be positioned into the fibular notch; a 3D image intensifier can be used to good effect to check the accuracy of the reduction. It is usually accomplished with a pointed reduction forceps and an at least tricortical positioning screw (33).

The positioning screw is not a traction screw. No pressure may be placed on the joint. The screw is usually placed about $2 \mathrm{~cm}$ above the tibial joint cleft in a $30^{\circ}$ orientation, from lateral-fibular to tibialventromedial. Avulsed bone fragments, such as a Wagstaffe fragment or a tubercle of Chaput, are put back in place with screws. Volkmann's triangle-a dorsal avulsion of the syndesmosis-should be repaired with one or two traction screws placed from the ventral side if more than $25 \%$ of the joint surface is involved.

Treatment with positioning screws carries the disadvantage that weight-bearing on the affected limb must be restricted for ca. six weeks (partial weightbearing up to a maximum of $10-20 \mathrm{~kg}$ ). At the end of this period, the syndesmosis is assumed to have

\section{A0/Danis-Weber type A fractures}

An isolated type $A$ fracture of the lateral malleolus should only be treated with open reduction and internal fixation (ORIF) if there are dislocated fragments and/or joint involvement.

\section{Injuries of the syndesmosis}

In any type $B$ or $C$ fracture, the ankle should be positioned intraoperatively in $20^{\circ}$ of internal rotation and pulled laterally with a retractor hook to test the stability of the syndesmosis. 
healed and the positioning screw can be removed. According to some studies, the positioning screw should be removed only if the patient is sympomatic (34); yet screws that are left in situ very often break, making the secondary removal of osteosynthetic material much more difficult (35). For high-performance athletes in particular, this generally implies an interruption of training for six weeks. Full weight-bearing in the presence of an indwelling positioning screw can cause stress-related complications up to and including a distal tibial fracture. Modern dynamic stabilization systems have shown promising results in the clinical trials that have been performed to date, but no definitive assessment is yet possible (36-39). The formal evidence level for the superiority of either conservative or surgical treatment is low at present and will remain so until better evidence is available (24).

\section{Difficult indications: treatment in the setting of major accompanying disease}

Decisions about treatment are often difficult for patients with diabetes and peripheral artery occlusive disease (PAOD), as well as for elderly patients with osteoporosis or "parchment skin." In these groups, the rate of wound infection is markedly elevated, to as much as $10 \%$ of all cases (40). In our experience, it can also be difficult to anchor a serviceable osteosynthesis in "soft" bone. Even if the operation itself is successful, poor compliance with weight-bearing after surgery after surgery can destroy the patient's chances of complication-free healing. In such situations, the immediate postoperative application of a walker or cast can be very helpful.

Pichl and Hoffmann have developed a highly practical algorithm for decision-making for elderly patients. The choice of treatment options, ranging from conservative or minimally invasive treatment all the way to plate osteosynthesis or external fixation, is allowed to depend on the state of the surrounding soft tissues, bone quality, and predicted compliance (e1).

\section{Complications \\ Acute complications}

The most common complications in the immediate postoperative period are wound hematoma and wound-edge necrosis. In doubtful cases, operative revision should be performed early and over a suffi- ciently wide area, in order to prevent infection and the development of larger defects that may, in the end, need plastic surgery to repair. The postoperative infection rate is up to $2 \%$. If wound healing is inadequate (sometimes with exposure of screws or plates), the osteosynthetic material should be removed (40). All exposed osteosynthetic material, i.e., material that is not covered by vital soft tissue, is considered infected per se. To wait for closure by second intention in such cases is contraindicated and, indeed, negligent.

In 2007, SooHoo published complication rates for various complications in a collective of 57000 fractures. The frequency of pulmonary embolism was $0.34 \%$, while the rate of wound infection was $1.44 \%$ and that of surgical revision was $0.82 \%$ (these three complications have been designated as occasional, common, and occasional, respectively, by the German Federal Institute for Drugs and Medical Devices-Bundesinstitut für Arzneimittel und Medizinprodukte, BfArM). The complication rate rises with increasing complexity of the injury and with increasing age (e2).

\section{Long-term complications}

Ankle arthrosis is the most serious long-term complication of ankle fractures (e3). Once all conservative treatments, including orthopedic shoes, have been tried, ankle arthrosis may need to be treated with a prosthetic ankle joint or an ankle arthrodesis (e3). According to Horisberger et al., the main risk factors for post-traumatic arthrosis are the type of fracture, impaired healing, the age of the patient at the time of the accident, and inadequate reconstruction of the joint surfaces and the ankle fork (including reconstruction in a varus or valgus malposition). In general, as many as $10 \%$ of all patients with an ankle fracture develop symptomatic ankle arthrosis over the intermediate or long term (e3-e5).

\section{Postoperative treatment and rehabilitation}

Adequate antithrombotic treatment should be given until full weight-bearing and full mobilization have been achieved.

In conservative treatment, the ankle is immobilized in a leg orthosis. This permits pain-adapted full weight-bearing in nearly all patients.

After surgery, inpatient rehabilitation is usually not indicated. Young and mobile patients with good

\section{Acute complications}

The most common complications in the immediate postoperative period are wound hematoma and wound-edge necrosis.

\section{Postoperative treatment and rehabilitation}

In conservative treatment, the ankle is immobilized in a leg orthosis. This permits pain-adapted full weight-bearing in nearly all patients. 
ankle mobility and without any ligamentous injury may need instruction in incremental weight-bearing or a "walking school" program. Most patients need early postoperative functional treatment with physiotherapeutic guidance to improve joint function and proprioception and to promote the regression of swelling (lymph drainage). Patients who have fractures combined with ligamentous injuries are particularly in need of proprioceptive physiotherapy to protect them from the risk of chronic ankle instability. Normally, a walker is not applied postoperatively, so that active and passive ankle motion is possible at all times. While the patient is still in the hospital, as soon as the state of the wound permits weight-bearing, partial weight-bearing up to 10-20 $\mathrm{kg}$ is initiated. After six weeks of partial weightbearing, a follow-up x-ray, and removal of positioning screws (if indicated), weight-bearing is incrementally increased in steps of $10 \mathrm{~kg}$ per week. As a rule, full weight-bearing and full participation in work and recreational sports are possible 12-16 weeks after the injury, or sooner in high-performance athletes. The level of evidence for optimal postoperative treatment is still low at present (e6).

\section{Conflict of interest statement}

The authors state that they have no conflicts of interest.

Manuscript submitted on 31 July 2013, revised version accepted on 19 March 2014.

Translated from the original German by Ethan Taub, M.D.

\section{REFERENCES}

1. Kannus P, Palvanen M, Niemi S, Parkkari J, Jarvinen M: Increasing number and incidence of low-trauma ankle fractures in elderly people: Finnish statistics during 1970-2000 and projections for the future. Bone 2002; 31: 430-3.

2. Hermans JJ, Beumer A, de Jong TA, Kleinrensink GJ: Anatomy of the distal tibiofibular syndesmosis in adults: a pictorial essay with a multimodality approach. Journal of anatomy 2010; 217: 633-45.

3. Pretterklieber ML: Anatomie und Kinematik der Sprunggelenke des Menschen. Der Radiologe 1999; 39: 1-7.

4. Thordarson DB, Motamed S, Hedman T, Ebramzadeh E, Bakshian IS: The effect of fibular malreduction on contact pressures in an ankle fracture malunion model. J Bone Joint Surg Am 1997; 79: 1809-15.

5. Ramsey PL, Hamilton W. Changes in tibiotalar area of contact caused by lateral talar shift. J Bone Joint Surg Am 1976; 58: 356-7.

6. Arbeitsunfähigkeit bei AOK-Pflichtmitgliedern 2013; www.gbebund.de Last accessed on $6^{\text {th }}$ of May 2014
7. Statistisches Bundesamt. 2012. www.destatis.de/DE/Publikationen/ Thematisch/Gesundheit/Krankenhaeuser/TiefgegliederteDiagnose daten.html, last accessed on 12 May 2014

8. Thur CK, Edgren G, Jansson KA, Wretenberg P. Epidemiology of adult ankle fractures in Sweden between 1987 and 2004: a population-based study of 91,410 Swedish inpatients. Acta orthopaedica 2012; 83: 276-81.

9. Court-Brown CM, McBirnie J, Wilson G: Adult ankle fractures —an increasing problem? Acta orthopaedica Scandinavica 1998; 69: 43-7.

10. Shearman A, Sarraf KM, Thevendran G, Houlihan-Burne D: Clinical assessment of adult ankle fractures. Br J Hosp Med 2013; 74: C37-40.

11. Stiell I, Wells G, Laupacis A, et al.: Multicentre trial to introduce the Ottawa ankle rules for use of radiography in acute ankle injuries. Multicentre Ankle Rule Study Group. BMJ 1995; 311: 594-7.

12. Saltzman CL, el-Khoury GY: The hindfoot alignment view. Foot Ankle Int 1995; 16: 572-6.

13. Black EM, Antoci V, Lee JT, et al.: Role of preoperative computed tomography scans in operative planning for malleolar ankle fractures. Foot \& ankle international. / American Orthopaedic Foot and Ankle Society [and] Swiss Foot and Ankle Society 2013; 34: 697-04.

14. Stäbler A, Szeimies U, Walther M: Radiologische Diagnostik des Fußes. Stuttgart: Thieme 2012.

15. Tscherne H, Oestern HJ: Die Klassifizierung des Weichteilschadens bei offenen und geschlossenen Frakturen. Unfallheilkunde 1982; 85: 111-15

16. Gustilo RB, Anderson JT: Prevention of infection in the treatment of one thousand and twenty-five open fractures of long bones: retrospective and prospective analyses. J Bone Joint Surg Am 1976; 58 453-8.

17. Gustilo RB, Mendoza RM, Williams DN: Problems in the management of type III (severe) open fractures: a new classification of type III open fractures. The Journal of trauma. 1984; 24: 742-6.

18. Nielsen JO, Dons-Jensen H, Sorensen HT: Lauge-Hansen classification of malleolar fractures. An assessment of the reproducibility in 118 cases. Acta orthopaedica Scandinavica 1990; 61: 385-7.

19. Weber B, Colton C: Malleolar fractures. In: Müller M, Allgöwer M, Schneider R, Willenegger H, eds.: Manual of internal fixation. Vol 3. Berlin: Springer; 1991: 595-612.

20. Weber B: Verletzungen des oberen Sprunggelenkes. Bern: Huber Verlag: 1966; 20

21. Park JW, Kim SK, Hong JS, Park JH: Anterior tibiofibular ligament avulsion fracture in weber type $B$ lateral malleolar fracture. The Journal of trauma 2002; 52: 655-9.

22. Dias LS, Giegerich CR: Fractures of the distal tibial epiphysis in adolescence. J Bone Joint Surg Am 1983; 65: 438-44.

23. Hoiness PR, Hvaal K, Engebretsen L: Severe hypothermic injury to the foot and ankle caused by continuous cryocompression therapy. Knee Surg Sports Traumatol Arthrosc 1998; 6: 253-55.

24. Donken CC, Al-Khateeb H, Verhofstad MH, van Laarhoven CJ: Surgical versus conservative interventions for treating ankle fractures in adults. The Cochrane database of systematic reviews 2012; 8: CD008470.

\section{Physiotherapy}

Most patients need early postoperative functional treatment with physiotherapeutic guidance to improve joint function and proprioception and to promote the regression of swelling (lymph drainage). 
25. Herscovici D, Jr., Scaduto JM, Infante A: Conservative treatment of isolated fractures of the medial malleolus. J Bone Joint Surg Br 2007; 89: 89-93.

26. Pelet S, Roger ME, Belzile EL, Bouchard M: The incidence of thromboembolic events in surgically treated ankle fracture. J Bone Joint Surg Am 2012; 94: 502-6.

27. Salai M, Dudkiewicz I, Novikov I, Amit Y, Chechick A: The epidemic of ankle fractures in the elderly - is surgical treatment warranted? Arch Orthop Trauma Surg 2000; 120: 511-3.

28. AWMF: Perioperative Antibiotikaprophylaxe. 2012. www.awmf.org/ leitlinien/detail//l/029-022.html. Last accessed on 10 May 2104.

29. Konrad G, Markmiller M, Lenich A, Mayr E, Ruter A: Tourniquets may increase postoperative swelling and pain after internal fixation of ankle fractures. Clinical orthopaedics and related research 2005 433: 189-94.

30. Chou LB, Lee DC: Current concept review: perioperative soft tissue management for foot and ankle fractures. Foot \& ankle international/American Orthopaedic Foot and Ankle Society [and] Swiss Foot and Ankle Society 2009; 30: 84-90.

31. Bonasia DE, Rossi R, Saltzman CL, Amendola A: The role of arthroscopy in the management of fractures about the ankle. J Am Acad Orthop Surg 2011; 19: 226-35.

32. Krettek C, Muller C, Meller R, Jagodzinski M, Hildebrand F, Gaulke $\mathrm{R}$ : Ist eine routinemäßige Implantatentfernung nach unfallchirurgischen Eingriffen sinnvoll? Der Unfallchirurg 2012; 115: 315-22.

33. Wikeroy AK, Hoiness PR, Andreassen GS, Hellund JC, Madsen JE: No difference in functional and radiographic results 8.4 years after quadricortical compared with tricortical syndesmosis fixation in ankle fractures. J Orthop Trauma 2010; 24: 17-23.

34. Tucker A, Street J, Kealey D, McDonald S, Stevenson M: Functional outcomes following syndesmotic fixation: A comparison of screws retained in situ versus routine removal-Is it really necessary? Injury 2013; 44: 1880-4.

35. Stuart K, Panchbhavi VK: The fate of syndesmotic screws. Foot Ankle Int 2011; 32: 519-25.

36. Schepers T: Acute distal tibiofibular syndesmosis injury: a systematic review of suture-button versus syndesmotic screw repair. International orthopaedics 2012; 36: 1199-1206.

37. Naqvi GA, Shafqat A, Awan N: Tightrope fixation of ankle syndesmosis injuries: clinical outcome, complications and technique modification. Injury 2012; 43: 838-4.

38. Egol KA, Pahk B, Walsh M, Tejwani NC, Davidovitch RI, Koval KJ: Outcome after unstable ankle fracture: effect of syndesmotic stabilization. J Orthop Trauma 2010; 24: 7-11.

39. Willmott HJ, Singh B, David LA: Outcome and complications of treatment of ankle diastasis with tightrope fixation. Injury 2009; 40: 1204-6.

40. Zaghloul A, Haddad B, Barksfield R, Davis B: Early complications of surgery in operative treatment of ankle fractures in those over 60 : A review of 186 cases. Injury 2014; 45: 780-3.

\section{Correspondence address}

Dr. med. Hans Goost

Krankenhaus Wermelskirchen

Abteilung für Orthopädie und Unfallchirurgie

Königstr. 100, 42929 Wermelskirchen, Germany

goost@krankenhaus-wermelskirchen.de

\section{Further information on GME}

This article has been certified by the North Rhine Academy for Postgraduate and Continuing Medical Education. Deutsches Ärzteblatt provides certified continuing medical education (CME) in accordance with the requirements of the Medical Associations of the German federal states (Länder). CME points of the Medical Associations can be acquired only through the Internet, not by mail or fax, by the use of the German version of the CME questionnaire. See the following website: cme.aerzteblatt.de.

Participants in the CME program can manage their CME points with their 15-digit "uniform CME number" (einheitliche Fortbildungsnummer, EFN). The EFN must be entered in the appropriate field in the cme.aerzteblatt.de website under "meine Daten" ("my data"), or upon registration. The EFN appears on each participant's CME certificate.

This CME unit can be accessed until 17 August 2014, and earlier CME units until the dates indicated:

"Not All Acne is Acne Vulgaris" (Issue 17/2014), 20 July 2014;

"The Differential Diagnosis and Treatment of Tremor" (13/2014), 22 June 2014;

"Structured Management of Otitis Media" (9/2014), 25 May 2014. 


\section{Please answer the following questions to participate in our certified Continuing Medical Education program. Only one answer is possible per question. Please select the answer that is most appropriate.}

\section{Question 1}

The ankle joint is formed by the distal ends of the tibia and fibula and the trochlea of the talus. What structures stabilize it medially?

a) The anterior fibulotalar ligament (AFTL), the fibulocalcanear ligament (FCL), and the posterior fibulotalar ligament (PFTL).

b) The wide fan of the deltoid ligament and the plantar cal-caneonavicular ligament (spring ligament), which is functionally a part of it.

c) The ligamentous structure of the syndesmosis.

d) The flexor hallucis longus and peroneus tertius muscles.

e) The ankle joint is a pure hinge joint with only two degrees of freedom and thus does not need medial stabilization.

\section{Question 2}

A 34-year-old man is injured in a fall from a motorcycle. An emergency physician on the scene notes an obvious malposition of the ankle joint. What should be done?

a) Hemostasis with a pressure dressing as the first priority

b) Fracture immobilization in a splint to prevent nerve injury

c) Immediate reduction by longitudinal traction with situationally appropriate analgesia

d) Immediate cooling to keep swelling down and enable early surgery

e) Application of an elastic pressure dressing to prevent further swelling; reduction only by a board-certified orthopedist/ traumatologist

\section{Question 3}

A 22-year-old physical-education student arrives in the emergency room at 9 p.m. after being injured in a volleyball game (national league). She has sustained a supination injury by landing on the right ankle after jumping up to block a ball at the net. Her ankle is only mildly swollen above the lateral malleolus, but she can only walk with a hobbling gait, with help from her coach. What considerations apply to the initial diagnostic evaluation?

a) Because of the patient's age, an MRI scan should be obtained at once to exclude a ligamentous injury.

b) Ligamentous avulsion is unlikely in a supination injury and, therefore, no imaging is needed.

c) On initial physical examination, before any imaging is done, the ankle should be extensively and forcefully tested for instability of the lateral ligaments. If no instability is evident, an $\mathrm{x}$-ray is unnecessary.

d) The physical examination should be performed delicately, and anteroposterior (fork view) and lateral plain films of the ankle should be obtained.

e) In Europe, CT scanning is standard in primary evaluation because there may be an accompanying midfoot injury.
Question 4

The patient from Question 3 is found to have a dislocated, displaced A0/Danis-Weber type B fracture and surgery is judged to be indicated. The soft tissues are not in critical condition or swollen; skin wrinkles are seen. What treatment should be provided, and with what goal?

a) Treatment with external fixation now and with plate osteosynthesis in approximately 14 days.

b) Anatomical reduction of the ankle fork and anatomical reconstruction of the length, axis, and rotation of the fibula as well as of the tibiotalar and fibulotalar distances.

c) Plate osteosynthesis and coverage of soft tissues that cannot be reapproximated with a vacuum dressing.

d) Image-guided reduction without surgery is adequate for this patient, obviating the need for skin incisions for the arthroscopy portals.

e) In the treatment of A0/Danis-Weber type B fractures plate systems are too costly and should not be used.

\section{Question 5}

Before signing the consent form, the patient asks again about the risks of the operation. What risks should she be told about?

a) Systemic complications such as pulmonary embolism are very common after surgery for ankle fractures, even in young, otherwise healthy patients.

b) The rate of infection is as high as $2 \%$ even if antibiotics are given as specified in the applicable guidelines.

c) In the ankle, unlike the hip and knee, post-traumatic arthrosis is very rare, even over the long term.

d) Wound hematomas and wound-edge necroses can be omitted from the informed-consent discussion, as this patient's injury is covered by good soft tissue.

e) There is no need to mention general surgical risks, because the operation is expected to be short.

\section{Question 6}

This patient's operation proceeds without complication. Two days later, she walks sturdily on crutches as instructed by a physiotherapist. What should her further treatment consist of?

a) Until full weight-bearing is achieved, she should be given subcutaneous injections of a low-molecular-weight heparin in a weight-adapted dose to prevent thrombosis.

b) She should have inpatient rehabilitation to lessen the chance of long-term disability.

c) If a positioning screw is used, it should be removed after no less than 12 weeks.

d) She should wear a forefoot-sparing shoe for 12 weeks.

e) To protect the soft tissues, a plaster cast should be applied after surgery and kept on for at least 6 weeks. 


\section{Question 7}

When can a patient with an ankle injury typically resume full weight-bearing and normal activity at work and in sports?
a) In 1-2 weeks
b) In 4-6 weeks
c) In 12-16 weeks
d) In 20 months
e) In a year

\section{Question 8}

What is the appropriate treatment of an isolated type A fracture of the lateral malleolus with a dislocated fragment?
a) This type of fracture generally heals without treatment.
b) A modern, dynamic stabilization system should be used.
c) Open reduction and internal fixation is appropriate.
d) A syndesmotic positioning screw should be used.
e) An angle-stable plate should be used.

\section{Question 9}

A lateral malleolar fracture below the syndesmosis is what type of injury in the expanded Danis-Weber classification?
a) Type $A$
b) Type B
c) Type C
d) Type D
e) Type E

\section{Question 10}

What is required for a metal removal procedure that is not medically indicated?
a) Immediate postoperative rehabilitation
b) Informed consent as for an elective cosmetic procedure
c) Referral from the prior operating surgeon
d) A doctor's certificate
e) Advance approval by the health-insurance carrier 